\title{
Nasal mucosal microRNA expression in children with respiratory syncytial virus infection
}

\author{
Christopher S Inchley ${ }^{1,2^{*}}$, Tonje Sonerud ${ }^{1,3}$, Hans O Fjærli ${ }^{1}$ and Britt Nakstad ${ }^{1,2}$
}

\begin{abstract}
Background: Respiratory syncytial virus (RSV) infection is a common cause of pediatric hospitalization. microRNA, key regulators of the immune system, have not previously been investigated in respiratory specimens during viral infection. We investigated microRNA expression in the nasal mucosa of 42 RSV-positive infants, also comparing microRNA expression between disease severity subgroups.

Methods: Nasal mucosa cytology specimens were collected from RSV-positive infants and healthy controls. 32 microRNA were selected by microarray for qPCR verification in 19 control, 16 mild, 7 moderate and 19 severe disease samples.

Results: Compared to healthy controls, RSV-positive infants downregulated miR-34b, miR-34c, miR-125b, miR-29c, mir125a, miR-429 and miR-27b and upregulated miR-155, miR-31, miR-203a, miR-16 and let-7d. On disease subgroups analysis, miR-125a and miR-429 were downregulated in mild disease ( $p=0.03$ and 0.02 , respectively), but not in severe disease $(p=0.3$ and 0.3$)$.

Conclusion: microRNA expression in nasal epithelium cytology brushings of RSV-positive infants shows a distinct profile of immune-associated miRNA. miR-125a has important functions within NF-kB signaling and macrophage function. The lack of downregulation of miR-125a and miR-429 in severe disease may help explain differences in disease manifestations on infection with RSV.
\end{abstract}

Keywords: Respiratory syncytial virus, MicroRNA, miR-34, miR-125, miR-429, miR-155, Bronchiolitis, Children, Pediatric, Nasal mucosa

\section{Background}

Respiratory syncytial virus (RSV) infection occurs in the majority of children during infancy [1]. Most children have mild upper respiratory symptoms such as coryza and cough. However, $2-3 \%$ of infants with RSV infection are admitted to hospital, presenting clinically with bronchiolitis or pneumonia [2]. Efforts to develop an effective vaccine have led to extensive investigation of the immune response to RSV. Patient-based immunological investigations in RSV disease commonly use the nasal mucosa as a proxy for the lower respiratory tract since the lower airways are rarely available for research purposes, and because limiting investigations only to intensive care patients may result in selection bias. RSV

\footnotetext{
* Correspondence: christopher.inchley@medisin.uio.no

'Department of Pediatric and Adolescent Medicine, Akershus University Hospital, 1478 Lørenskog, Norway

${ }^{2}$ Institute of Clinical Medicine, University of Oslo, 0316 Oslo, Norway

Full list of author information is available at the end of the article
}

preferentially infects epithelial cells of the respiratory mucosa, initiating an innate immune reaction with infiltration of granulocytes and other myeloid cells, production of a range of cytokines and activation of dendritic cells [3].

microRNAs (miRNAs) are non-coding small RNA sequences that inhibit translation of messenger RNA (mRNA) to protein by binding to specific target mRNA [4]. Studies in recent years have demonstrated their role in the regulation of multiple biological pathways within the innate and adaptive immune systems. These pathways include negative feedback mechanisms to prevent an excessive immune reaction, pathways governing cell fate decisions and communication between innate and adaptive immune systems $[5,6]$. Several studies have investigated miRNA responses to RSV in-vitro [7-9], but to date there are no published investigations of miRNA regulation in clinical RSV disease. We have previously 
described an association between downregulation of Dicer at birth and severe infantile RSV disease [10]. Since Dicer is a key protein in miRNA biogenesis, we considered that differential Dicer expression on infection may result in altered miRNA profiles, which may in turn explain why some children develop severe disease.

The aim of this investigation was two-fold: i) to describe miRNAs involved in the immune response to RSV in a clinical setting; ii) to discover differences in miRNA expression between disease severity groups. We have therefore profiled miRNA in cytology brushings of the nasal mucosa in infants with RSV disease, comparing them to healthy infants.

\section{Methods}

\section{Patient selection}

Study inclusion was during the RSV season in Akershus, Norway, from January to March 2011. Infants < 12 months of age examined on the pediatric emergency unit at our hospital with an upper or lower airways infection were considered for inclusion. A nasopharyngeal aspirate (NPA) for virus detection and nasal mucosal cytology specimens were taken from eligible patients on admission. Those testing positive for RSV by either rapid antigen testing or multiplex RT-PCR were included in the study.

\section{Exclusion criteria}

Patients born before 34 weeks gestation, with bronchopulmonary dysplasia, chronic lung disease including treated asthma, neurological disease, Down syndrome, hypotonia, failure to thrive, or other specific conditions likely to contribute to a more severe course of disease were excluded from the study.

\section{Respiratory distress}

Patients were included prospectively and assessed by the treating pediatrician for respiratory distress using a modified Respiratory Distress Assessment Instrument (m-RDAI), developed for this study from a validated scoring system to allow a single measure of respiratory rate [11]. The m-RDAI is described further in Table 1.

\section{Disease severity}

For disease severity subgroup analyses, infants were classified into mild, moderate or severe disease groups. The severe disease group included infants requiring mechanical ventilation, CPAP, supplemental oxygen or supplemental fluids (intravenous or nasogastric tube). Infants who were admitted and who did not receive any of the treatments described for severe disease were classified with mild disease if they had an $\mathrm{m}$-RDAI $\leq 8$ and with moderate disease if they had an m-RDAI $9-25$. All infants who were not admitted were classified with mild disease, irrespective of m-RDAI score.

\section{Control group}

A control group of infants was recruited during routine visits to family health clinics in our catchment area. Control infants were included if they were healthy, without signs of upper or lower respiratory disease.

\section{Nasal samples for virus and miRNA analysis}

NPAs were taken from both nostrils by deep nasal suctioning. RSV infection was confirmed using a rapid antigen test (BinaxNOW RSV Card, Alere, Waltham, Massachusetts, USA) and/or in-house RT-PCR. After removal of respiratory secretions by NPA, nasal epithelial cells were sampled from each nostril by rotating a cytology brush (Medscand Medical Cytobrush Plus, CooperSurgical, Trumbull,

Table 1 Modified respiratory distress assessment instrument (m-RDAI)

\begin{tabular}{|c|c|c|c|c|c|}
\hline Points & 0 & 1 & 2 & 3 & 4 \\
\hline \multicolumn{6}{|l|}{ Wheeze } \\
\hline Expiration & None & End-Expiratory & $1 / 2$ & \multirow[t]{3}{*}{$3 / 4$} & Whole expiration \\
\hline Inspiration & None & Partly & Whole inspiration & & \\
\hline Location & None & $\leq 2$ of 4 lung fields & $\geq 3$ of 4 lung fields & & \\
\hline \multicolumn{6}{|l|}{ Retractions } \\
\hline Supraclavicular & No & Mild & Moderate & \multicolumn{2}{|l|}{ Significant } \\
\hline Intercostal & No & Mild & Moderate & \multicolumn{2}{|l|}{ Significant } \\
\hline Subcostal & No & Mild & Moderate & \multicolumn{2}{|l|}{ Significant } \\
\hline Respiratory Rate & & \multicolumn{2}{|c|}{ Upper limit of normal respiratory rate } & \multicolumn{2}{|l|}{ Points } \\
\hline Age $<1$ month & & \multicolumn{2}{|l|}{$50 / \min$} & \multirow{3}{*}{\multicolumn{2}{|c|}{$\begin{array}{l}1 \text { point for each increment of } 5 \text { breaths/minute } \\
\text { above normal, max. } 8 \text { points }\end{array}$}} \\
\hline Age 1 - 5 months & & \multicolumn{2}{|l|}{$40 / \min$} & & \\
\hline Age $6-11$ months & & \multicolumn{2}{|l|}{$30 / \min$} & & \\
\hline
\end{tabular}

Note: Maximum score for wheeze - 8 points; for retractions - 9 points; for respiratory rate - 8 points. Thus RR, retractions and wheeze are equally weighted. Maximum m-RDAl score is 25 points. Adapted from Lowell et al. [11]. Example - a 3-month old child with a respiratory rate of 62 receives 5 points for Respiratory rate $(62-40=22 ; 22 / 5=4.4$; round up to 5$)$. 
Connecticut, USA) over the anterior nasal mucosa. Brushes were immediately immersed in RNA stabilization reagent RNAlater (Catalog Number R0901, Sigma-Aldrich, Saint Louis, Missouri, USA). Epithelial cells were detached from the brushes and stored at $-80^{\circ} \mathrm{C}$ in RNAlater for miRNA analysis.

\section{Cytology}

Cytology specimens from 7 infants with mild, and 5 infants with severe disease were smeared onto a microscopy slide for visual assessment of cell type.

\section{RNA isolation}

Epithelial cells stored at $-80^{\circ} \mathrm{C}$ were pelleted before homogenization in QIAzolLysis Reagent (Qiagen, Hilden, Germany). The miRNeasy mini kit (Qiagen) was then used according to the manufacturer's instructions with additional DNase treatment. Because of low yield in the control samples, these were pooled into age and gender-matched pairs during RNA isolation.

\section{RNA quality control}

We used the NanoDrop ND-1000 Spectrophotometer (NanoDrop Technologies) and Agilent 2100 Bioanalyzer to assess RNA purity and integrity using the $260 / 280$ ratio, the $260 / 230$ ratio and the RNA integrity number (RIN).

\section{miRNA Microarray}

miRNA expression profiling was performed on 48 samples on Agilent Human miRNA Microarray Release 14.0, 8x15K slides using Agilent's miRNA Microarray System protocol together with miRNA Spike-In Kit and miRNA Complete Labeling and Hyb Kit. A single color array was used. Arrays were scanned on Agilent G2565BA Microarray Scanner. Data collection and quality assessment were performed using Agilent Feature Extraction Software v8.5. Microarray results are deposited in NCBI's Gene Expression Omnibus [12] with accession number GSE62306.

\section{miRNA qPCR}

miRNA differentially expressed between control and disease groups were selected from the microarray for qPCR verification. qPCR was done using looped miRNAspecific RT-primers and sequence-specific TaqMan miRNA Assays from Life Technologies (Table 2). The protocol for creating custom RT and pre-amplification pools using TaqMan Assays was used. RT and PreAmp were performed according to protocol using $60 \mathrm{ng}$ total RNA in the RT-reaction. The PreAmp product was diluted 32,8 times and $4 \mu \mathrm{l}$ were run in a total reaction volume of $25 \mu \mathrm{l}$ in qPCR. The final concentration of TaqMan MicroRNA Assay used was 1x together with 1x TaqMan Universal Master Mix II, with UNG and nuclease-free water. The reverse transcription (RT) pool was made combining $10 \mu \mathrm{l}$ of each $5 x \mathrm{RT}$ primer in a total volume of $1000 \mu \mathrm{l}$ with 1xTE. $10 \mu \mathrm{l}$ of each 20x TaqMan MicroRNA Assay were combined in a total volume of $1000 \mu \mathrm{l}$ with $1 x T E$ in the pre-amplification. Samples were run in duplicates on ABI PRISM 7900 HT Fast qPCR system and analyzed using ABI Prism SDS2.4 software (Life Technologies). RNU24 was selected as a reference gene for normalization after pre-validation for expression stability in a sub-set of our samples. Samples were normalized and calibrated using the $\Delta \Delta$ Cq method.

\section{Statistical analysis}

Microarray results were analyzed using the $\mathrm{R}$ computing environment [13]. The AgiMiRNA package with quantile normalization [14] was used for pre-processing. Microarray performance was assessed using relative log expression and principal component analysis. The Linear models for microarray (Limma) package with an empirical Bayes approach [15] was used for statistical analysis. P-values were adjusted for multiple testing using a false discovery rate of $5 \%$. Adjusted p-values $<0.05$ were considered statistically significant.

PCR results were analyzed using IBM SPSS 20.0 software and the $\mathrm{R}$ computing environment. First, RSV positive samples were compared to controls using a multivariate linear regression model with adjustment for the RNA integrity number (RIN). There were no significant correlations between age or gender and individual miRNA expression or disease group. These variables were therefore not included in the multiple regression analysis. Significance values were adjusted for multiple testing using a false discovery rate of $5 \%$.

Secondly, for each miRNA, boxplots of control and disease subgroups were created. miRNAs that showed visual evidence of differential expression between disease groups were selected for analysis using one-way ANOVA (adjusted for a false discovery rate of 5\%), followed by Dunnett's test, comparing all disease groups to the control group.

\section{Ethical issues}

Written, informed consent was obtained from the guardians of all infants prior to inclusion. The Regional Committee for Medical and Health Research Ethics, South-East Norway and the data-protection officer at Akershus University Hospital approved the study protocol.

\section{Results}

Nasal samples were taken from 105 eligible RSV-positive infants, including 40 with mild, 25 with moderate and 40 with severe disease. Fifty-nine control samples were available. 61 samples had sufficient yield and RNA quality for qPCR analysis. 
Table 2 miRBase IDs and mature miRNA sequences for miRNAs included in the $\mathrm{QPCR}$ verification

\begin{tabular}{|c|c|c|c|}
\hline miRBase ID & Accession $^{1}$ & Assay $^{2}$ & Mature miRNA Sequence \\
\hline hsa-let-7d-5p & Ml0000065 & 002283 & $\begin{array}{l}\text { AGAGGUAGUAGGUUGCAU } \\
\text { AGUU }\end{array}$ \\
\hline hsa-let-7f-5p & MIMAT0000067 & 000382 & $\begin{array}{l}\text { UGAGGUAGUAGAUUGUAU } \\
\text { AGUU }\end{array}$ \\
\hline hsa-let-7g-5p & MIMAT0000414 & 002282 & $\begin{array}{l}\text { UGAGGUAGUAGUUUGUAC } \\
\text { AGUU }\end{array}$ \\
\hline hsa-let-7i-5p & MIMAT0000415 & 002221 & $\begin{array}{l}\text { UGAGGUAGUAGUUUGUGC } \\
\text { UGUU }\end{array}$ \\
\hline hsa-miR-16-5p & MIMAT0000069 & 000391 & $\begin{array}{l}\text { UAGCAGCACGUAAAUAUU } \\
\text { GGCG }\end{array}$ \\
\hline hsa-miR-19a-3p & MIMAT0000073 & 000395 & $\begin{array}{l}\text { UGUGCAAAUCUAUGCAAA } \\
\text { ACUGA }\end{array}$ \\
\hline hsa-miR-21-5p & MIMAT0000076 & 000397 & $\begin{array}{l}\text { UAGCUUAUCAGACUGAUG } \\
\text { UUGA }\end{array}$ \\
\hline hsa-miR-23b-3p & MIMAT0000418 & 000400 & $\begin{array}{l}\text { AUCACAUUGCCAGGGAU } \\
\text { UACC }\end{array}$ \\
\hline hsa-miR-26b-5p & MIMAT0000083 & 000407 & $\begin{array}{l}\text { UUCAAGUAAUUCAGGAU } \\
\text { AGGU }\end{array}$ \\
\hline hsa-miR-27b-3p & MIMAT0000419 & 000409 & $\begin{array}{l}\text { UUCACAGUGGCUAAGUU } \\
\text { CUGC }\end{array}$ \\
\hline hsa-miR-29c-3p & MIMAT0000681 & 000587 & $\begin{array}{l}\text { UAGCACCAUUUGAAAUC } \\
\text { GGUUA }\end{array}$ \\
\hline hsa-miR-30b-5p & MIMAT0000420 & 000602 & $\begin{array}{l}\text { UGUAAACAUCCUACACU } \\
\text { CAGCU }\end{array}$ \\
\hline hsa-miR-30d-5p & MIMAT0000245 & 000420 & $\begin{array}{l}\text { UGUAAACAUCCCCGACU } \\
\text { GGAAG }\end{array}$ \\
\hline hsa-miR-31-5p & MIMAT0000089 & 002279 & $\begin{array}{l}\text { AGGCAAGAUGCUGGCAU } \\
\text { AGCU }\end{array}$ \\
\hline hsa-miR-34b-5p & MIMAT0000685 & 000427 & $\begin{array}{l}\text { UAGGCAGUGUCAUUAGC } \\
\text { UGAUUG }\end{array}$ \\
\hline hsa-miR-34c-5p & MIMAT0000686 & 000428 & $\begin{array}{l}\text { AGGCAGUGUAGUUAGCU } \\
\text { GAUUGC }\end{array}$ \\
\hline hsa-miR-96-5p & MIMAT0000095 & 000186 & $\begin{array}{l}\text { UUUGGCACUAGCACAUU } \\
\text { UUUGCU }\end{array}$ \\
\hline hsa-miR-125a-5p & MIMAT0000443 & 002198 & $\begin{array}{l}\text { UCCCUGAGACCCUUUAA } \\
\text { CCUGUGA }\end{array}$ \\
\hline hsa-miR-125b-5p & MIMAT0000423 & 000449 & $\begin{array}{l}\text { UCCCUGAGACCCUAACU } \\
\text { UGUGA }\end{array}$ \\
\hline hsa-miR-130a-3p & MIMAT0000425 & 000454 & $\begin{array}{l}\text { CAGUGCAAUGUUAAAA } \\
\text { GGGCAU }\end{array}$ \\
\hline hsa-miR-146a-5p & MIMAT0000449 & 000468 & $\begin{array}{l}\text { UGAGAACUGAAUUCCA } \\
\text { UGGGUU }\end{array}$ \\
\hline hsa-miR-148a-3p & MIMAT0000243 & 000470 & $\begin{array}{l}\text { UCAGUGCACUACAGAA } \\
\text { CUUUGU }\end{array}$ \\
\hline hsa-miR-155-5p & MIMAT0000646 & 002623 & $\begin{array}{l}\text { UUAAUGCUAAUCGUGA } \\
\text { UAGGGGU }\end{array}$ \\
\hline hsa-miR-183-5p & MIMAT0000261 & 002269 & $\begin{array}{l}\text { UAUGGCACUGGUAGAA } \\
\text { UUCACU }\end{array}$ \\
\hline hsa-miR-200b-5p & MIMAT0004571 & 002274 & $\begin{array}{l}\text { CAUCUUACUGGGCAGC } \\
\text { AUUGGA }\end{array}$ \\
\hline hsa-miR-203a & MI0000283 & 000507 & $\begin{array}{l}\text { GUGAAAUGUUUAGGA } \\
\text { CCACUAG }\end{array}$ \\
\hline
\end{tabular}

Table 2 miRBase IDs and mature miRNA sequences for miRNAs included in the qPCR verification (Continued)

\begin{tabular}{|c|c|c|c|}
\hline hsa-miR-205-5p & MIMAT0000266 & 000509 & $\begin{array}{l}\text { UCCUUCAUUCCACCGG } \\
\text { AGUCUG }\end{array}$ \\
\hline hsa-miR-223-3p & MIMAT0000280 & 002295 & $\begin{array}{l}\text { UGUCAGUUUGUCAAAU } \\
\text { ACCCCA }\end{array}$ \\
\hline hsa-miR-324-3p & MIMAT0000762 & 002161 & $\begin{array}{l}\text { ACUGCCCCAGGUGCUG } \\
\text { CUGG }\end{array}$ \\
\hline hsa-miR-331-3p & MIMAT0000760 & 000545 & $\begin{array}{l}\text { GCCCCUGGGCCUAUCC } \\
\text { UAGAA }\end{array}$ \\
\hline hsa-miR-375 & MI0000783 & 000564 & $\begin{array}{l}\text { UUUGUUCGUUCGGCUC } \\
\text { GCGUGA }\end{array}$ \\
\hline hsa-miR-429 & Ml0001641 & 001024 & $\begin{array}{l}\text { UAAUACUGUCUGGUAA } \\
\text { AACCGU }\end{array}$ \\
\hline
\end{tabular}

${ }^{1}$ miRBase accession number [41]

${ }^{2}$ Life Technologies' assay ID.

The 12 samples assessed by microscopy had an abundance of squamous and ciliary epithelial cells, and granulocytes, confirming that our samples included nasal mucosal cells, not simply mucous secretions. There were no obvious differences between mild and severe disease.

\section{Microarray}

14 severe RSV, 13 mild RSV and 13 control samples were analyzed. Of 887 miRNA included on the microarray; 190 were detectable. Limma analysis of control, mild and severe disease revealed 14 differentially expressed miRNA. A further 12 miRNAs were differently expressed in pairwise comparisons between groups. Results for significantly regulated miRNA are presented in Figure 1 as a heatmap. miRNA are classified according to the pattern of expression. These 26 miRNA were selected for qPCR verification alongside miR-23b, miR-30b, miR-223, miR-146a, miR-155 and miR-21, which have well described roles in the immune system but were not differentially expressed in the microarray.

\section{qPCR}

Fourty-two RSV-positive and 19 control samples with were analyzed by qPCR, including 16 with mild, 7 with moderate and 19 with severe disease. Table 3 shows clinical characteristics of these infants. In order to increase the power of the analysis, 9 control and 20 RSV-positive samples included in the microarray were also included in the qPCR.

Figure 2 shows the comparison of disease versus control for all 32 miRNAs analyzed by qPCR. miR-34b, miR-34c, miR-125b, miR-29c, mir125a, miR-429 and miR-27b were significantly downregulated. miR-155, miR-31, miR-203a, miR-16 and let-7d were significantly upregulated. Known immune functions of these miRNA are summarized in Table 4. 

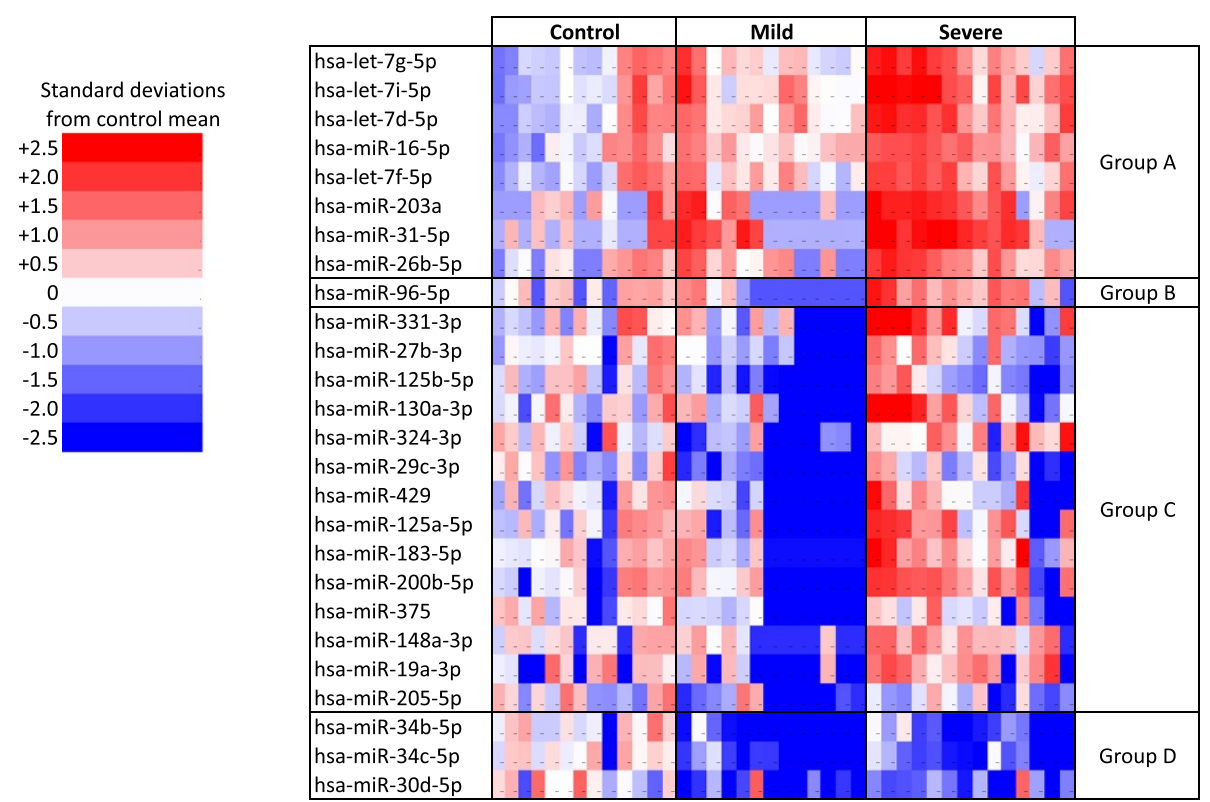

Figure 1 miRNA Microarray of nasal mucosa brushings in infants infected with Respiratory syncytial virus, compared to healthy controls. Note: Only miRNAs significant in the microarray $(p<0.05$, adjusted for a false discovery rate of $5 \%)$ are shown. For each miRNA, results are calibrated to the mean of the control group for that miRNA. Number of samples: Control 13, Mild RSV disease 13; Severe RSV disease 14. miRNAs are grouped according to results of Limma analysis, as compared to the control group: Group A: Upregulation in RSV disease. Group B: Upregulation in severe disease; downregulation in mild disease. Group C: Downregulation in mild disease; not regulated in severe disease. Group D: Downregulation in RSV disease.

\section{Disease subgroups}

miR-125a and mir-429 showed evidence of differential expression between disease subgroups (Figure 3). Compared to control, the mild and moderate disease subgroups show miR-125a downregulation, but not the severe disease subgroup. miR-429 shows a similar pattern, except that the downregulation in the moderate group is not quite significant.

\section{Discussion}

We have profiled miRNA expression in nasal epithelial cells of infants with acute RSV disease, compared to healthy controls. In addition we find differential expression between mild, moderate and severe disease groups for miR-125a and miR-429.

Bronchiolitis is a disease in which the entire respiratory tract is affected, with both upper and lower respiratory symptoms in the majority of children. Ethical considerations limited this investigation to the nasal mucosa since we were interested in infants not receiving intensive care treatment. Several cell types were present in our samples: granulocytes, squamous epithelial cells and ciliary epithelial cells. We are therefore unable to make direct conclusions about miRNA expression in cells of the lower respiratory tract or individual cell types. We do, however, consider that the nasal mucosa is a reasonable site to examine the immunological response to RSV infection. The nasal cavity is the primary site of RSV infection, and children typically have coryza for several days prior to lower respiratory symptoms. Differences in the nasal mucosal immune response may increase the risk of severe disease, for example by promoting dissemination of viral particles to the lower respiratory tract, or by increasing mucous production and inflammation.

RSV preferentially infects epithelial cells of the respiratory mucosa. We differentiated between disease severities in the setting of patients routinely admitted to hospital, such that severe disease patients were largely treated on the pediatric ward, not the intensive care unit. Severe disease was distinguished from moderate disease on the basis of supplemental oxygen or fluids, or use of CPAP. It is therefore interesting that on admission, those in the moderate disease group tended to more respiratory distress than those in the severe disease group, as measured by the m-RDAI (Table 3 ). This is a similar pattern to the PCR findings for miR-125a, and miR-429, where there is regulation in mild or moderate disease groups that is not present in the severe disease group. Increased signs of respiratory effort may be a protective factor, and infants who do not show these signs may either be too tired to increase their work of breathing, or may not have this capacity for other reasons - for example the body's drive (immunological or otherwise) to respond to infection. Clinical findings should, however, 
Table 3 Clinical characteristics of control and RSV-positive infants included in the qPCR analysis

\begin{tabular}{|c|c|c|c|c|c|c|c|c|c|}
\hline \multirow[b]{2}{*}{ Number } & \multicolumn{2}{|c|}{ Control } & \multicolumn{2}{|l|}{ Mild } & \multicolumn{2}{|c|}{ Moderate } & \multicolumn{2}{|c|}{ Severe } & \multirow[t]{2}{*}{ Sig. } \\
\hline & 19 & & 16 & & 7 & & 19 & & \\
\hline Age - months, median (IQR) & 3 & $(1-5)$ & 4 & $(1-7)$ & 2 & $(1-4)$ & 2 & $(1-4)$ & $p=0.6^{1}$ \\
\hline Male gender, n (\%) & 11 & $(58 \%)$ & 7 & $(44 \%)$ & 6 & $(86 \%)$ & 9 & $(47 \%)$ & $p=0.5^{2}$ \\
\hline Weight - g, mean (SD) & 5773 & $(1647)$ & 7098 & $(2350)$ & 6615 & $(1392)$ & 5826 & $(1845)$ & $p=0.2^{3}$ \\
\hline Duration of symptoms - days, median (IQR) & & & 4.5 & $(3-6)$ & 5 & $(4-5)$ & 4 & $(3-5)$ & $p=0.7^{4}$ \\
\hline Admission, n (\%) & & & 2 & $(13 \%)$ & 7 & $(100 \%)$ & 19 & $(100 \%)$ & \\
\hline Length of stay, median (IQR) & & & 0 & $(0-0)$ & 3 & $(1-4)$ & 4 & $(2-6)$ & $p=0.3^{5}$ \\
\hline Length of stay > 3 days, $n$ (\%) & & & 0 & $(0 \%)$ & 2 & $(29 \%)$ & 10 & $(56 \%)$ & $p=0.2^{6}$ \\
\hline \multicolumn{10}{|l|}{ Respiratory Distress } \\
\hline SpO2 -\% on admission, mean (SD) & & & 98 & $(2.5)$ & 98 & $(2.5)$ & 93 & (6) & $p=0.003^{7}$ \\
\hline Respiratory rate /min on admission, mean (SD) & & & 50 & $(14)$ & 57 & (8) & 61 & (13) & $p=0.06^{7}$ \\
\hline Respiratory rate score (max. 8), median (IQR) & & & 1.5 & $(0-5)$ & 4 & $(2-6)$ & 4 & $(2-6)$ & $p=0.16^{4}$ \\
\hline Retraction score (max. 9), median (IQR) & & & 1 & $(0-2)$ & 5 & $(2-6)$ & 2 & $(1-4)$ & $p=0.006^{4}$ \\
\hline Wheeze score (max. 8), median (IQR) & & & 1 & $(0-3)$ & 4 & $(4-5)$ & 2 & $(2-4.5)$ & $p=0.053^{4}$ \\
\hline \multirow[t]{2}{*}{ m-RDAI, median (IQR) } & & & 6 & $(1-8)$ & 13 & $(9-16)$ & 9 & $(7-13)$ & $p=0.004^{4}$ \\
\hline & & & & & & & & & $p=0.09^{5}$ \\
\hline \multicolumn{10}{|l|}{ Treatments } \\
\hline Fluid supplement, n (\%) & & & & & & & 8 & $(42 \%)$ & \\
\hline Intravenous fluids, n (\%) & & & & & & & 2 & $(11 \%)$ & \\
\hline Nasogastric fluid, n (\%) & & & & & & & 7 & $(37 \%)$ & \\
\hline Oxygen supplement, n (\%) & & & & & & & 16 & $(84 \%)$ & \\
\hline CPAP, n (\%) & & & & & & & 3 & $(16 \%)$ & \\
\hline Respirator, n (\%) & & & & & & & 0 & & \\
\hline
\end{tabular}

Note: There are no significant differences in age, weight or gender between control and RSV-positive groups. Duration of symptoms for disease subgroups was similar. The severe disease group had a lower SpO2 on admission, but tended to less respiratory distress than the moderate group, as measured by the m-RDAl. The retraction score in particular contributed to this difference. Length of hospital stay was statistically similar for moderate and severe disease groups, probably due to loss of power when excluding samples with poor RNA quality (when including all children regardless of RNA quality, the median length of stay and IQR are relatively unchanged, but Mann-Whitney $p=0.048$, indicating a longer hospital stay for the severe disease group). The most common treatment for children with severe disease was oxygen supplementation.

${ }^{1}$ Mann-Whitney test, comparing control group with RSV-positive group.

${ }^{2}$ Fischer's exact test, comparing control group with RSV-positive group.

${ }^{3} T$-test, comparing control group with RSV-positive group.

${ }^{4}$ Kruskal-Wallis test, comparing disease severity subgroups.

${ }^{5}$ Mann-Whitney test, comparing moderate and severe disease subgroups.

${ }^{6}$ Fischer's exact test, comparing moderate and severe disease subgroups.

${ }^{7}$ One-way ANOVA, comparing disease severity subgroups.

be interpreted with caution because the m-RDAI was only measured on admission. If we had re-assessed respiratory effort during the course of the admission we may have discovered an increased score prior to oxygen or fluid administration. In this prospective study, an arbitrary m-RDAI cut-off was used to distinguish mild from moderate disease groups in admitted patients. Only two mild disease patients included in the final analysis were admitted, and both of these had an m-RDAI score of 6, largely due to tachypnea, with little wheeze and few retractions. We therefore consider these patients to be correctly categorized.

26 miRNAs were differentially regulated in the microarray. 11 of these were also differentially regulated in the qPCR. Of the 6 miRNA not differentially regulated in the microarray, one (miR-155) was differentially regulated in the qPCR. For miRNA regulated in both microarray and $\mathrm{qPCR}$, the pattern of regulation was similar in the two analyses when grouping all RSV positive children together (Figures 1 and 2). On subgroup analysis, miRNA group $C$ (see Figure 1) is of interest. Group $C$ includes miRNA downregulated in mild disease but not in severe disease. miR-125a and miR-429 are in this group, and qPCR subgroup analysis was consistent with the microarray. miR-125b, miR-27b and miR-29c were also in this group but did not show differences between disease groups. The other 12 group $\mathrm{C}$ miRNA were not differentially regulated in the qPCR. The use of clinical samples with a high degree of biologically variation, the fact that microarray is less precise than qPCR, the low 


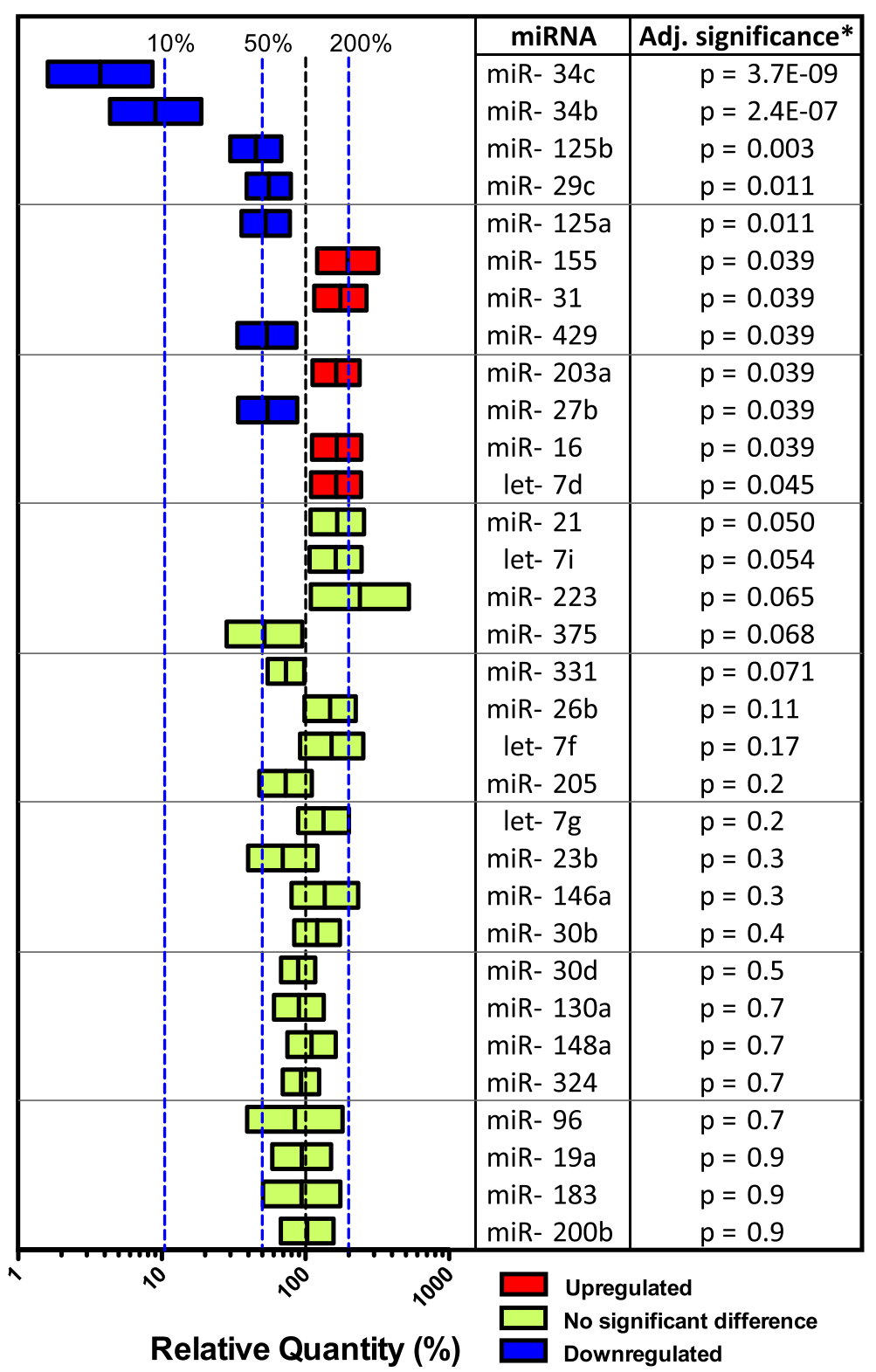

Figure 2 Nasal mucosal miRNA expression in infants infected with Respiratory syncytial virus, compared to healthy controls. Note: Samples from 42 children with RSV were compared to 19 control samples using qPCR for selected miRNA. Values presented are mean differences between disease and control groups with $95 \%$ confidence interval. * Multiple linear regression analysis with correction for RIN. p-values are adjusted for a false discovery rate of $5 \%$.

number of samples in each group, and the increased number of samples in the qPCR may explain differences between microarray and qPCR results.

The majority of miRNAs regulated in this study have documented functions within the immune system (see Table 4). Expression levels of miR-34c, miR-34b and miR-125b were reduced more than two-fold compared to control, with significance levels several orders of magnitude greater than the other regulated miRNAs, suggesting that downregulation of these miRNAs in particular may be important in the immune response to RSV.
One report described miR-34c upregulation by adult peripheral blood monocytes on exposure to damageassociated molecular pattern molecules. In the same paper miR-34c negatively regulated NF- $\mathrm{kB}$ signaling by inhibition of Inhibitor of IKK $\gamma[16]$. Another study showed miR-34c upregulation in umbilical cord blood monocytes on exposure to the Th1 cytokine interferon- $\gamma$, but not on exposure to lipopolysaccharide [17]. miR-125b has been well studied, and a number of functions within the immune system are described, including regulation of NF- $\kappa B$ signaling [18,19], macrophage activation [20], 
Table 4 Functions, known targets and disease associations of differentially expressed miRNA

\begin{tabular}{|c|c|c|c|c|}
\hline miRNA & Expression in this study & Functions in the immune system ${ }^{\dagger}$ & Specific targets $^{\dagger}$ & $\begin{array}{l}\text { Disease associations } \\
\text { (Human studies) }\end{array}$ \\
\hline \multicolumn{5}{|c|}{ Both innate and adaptive immune functions } \\
\hline \multirow[t]{2}{*}{ miR-29c } & Downregulation & Positive regulation of NFKB signaling [26] & TNFAIP3 [26] & Tuberculosis - upregulated [42] \\
\hline & & Influenza $\rightarrow$ Upregulation. ${ }^{\dagger \dagger}$ Promotes apoptosis [43] & BCL2L2 [43] & Asthma - downregulated [37] \\
\hline miR-31 & Upregulation & Proliferation of myeloid cells [33] & E-selectin [44] & Influenza - downregulated [35] \\
\hline \multirow[t]{4}{*}{ miR-155 } & Upregulation & Proliferation of myeloid cells [33] & SHIP1 [33] & Influenza - downregulated [35] \\
\hline & & Dendritic cell maturation $[34,45]$ & $\begin{array}{l}\text { PU.1 [45], SOCS1, } \\
\text { CD115, KPC1 [34] }\end{array}$ & \\
\hline & & Positive regulation of TLR signaling [18] & SOCS1 [18] & \\
\hline & & Required for dendritic, B and T-cell function [32] & & \\
\hline \multirow[t]{2}{*}{ let-7d } & Upregulation & Promotes $T_{h} 1$ polarization [40] & IL13 [40] & Asthma - downregulated [46] \\
\hline & & Endotoxin $\rightarrow$ Upregulation (TLR4 dep.) ${ }^{+\dagger}[23]$ & & \\
\hline
\end{tabular}

Primarily innate immune functions

\begin{tabular}{|c|c|c|c|c|}
\hline \multirow[t]{4}{*}{ miR-16 } & \multirow[t]{4}{*}{ Upregulation } & Negative regulation of inflammation [47] & TNFa [47] & \multirow[t]{4}{*}{ Sepsis - improved survival [48] } \\
\hline & & Positive regulation of NFKB signaling [24] & SMRT [24] & \\
\hline & & Negative regulation of NFKB signaling [28] & IKKa [28] & \\
\hline & & Endotoxin $\rightarrow$ Upregulation (TLR4 dep) ${ }^{\dagger+}[23]$ & & \\
\hline \multirow[t]{2}{*}{$\operatorname{miR}-27 b$} & \multirow[t]{2}{*}{ Downregulation } & TLR4/NFKB induced nitric oxide production [49] & KSRP [49] & \multirow[t]{2}{*}{ Asthma - downregulated [37] } \\
\hline & & Endotoxin $\rightarrow$ Upregulation (NFKB dep) ${ }^{\text {t+ }}[50]$ & & \\
\hline miR-34b & Downregulation & Endotoxin $\rightarrow$ Upregulation (TLR4 dep) ${ }^{+\dagger}[23]$ & & Asthma - downregulated [37] \\
\hline \multirow[t]{2}{*}{ miR-34c } & \multirow[t]{2}{*}{ Downregulation } & $\begin{array}{l}\text { Negative regulation of NFKB signaling; DAMPs* } \rightarrow \\
\text { Upregulation [16] }\end{array}$ & IKKY [16] & \multirow[t]{5}{*}{ Asthma - downregulated [37] } \\
\hline & & $\begin{array}{l}\text { In cord blood monocytes: IFNy } \rightarrow \text { Upregulation }{ }^{\dagger+} \\
\text { Endotoxin } \rightarrow \text { no regulation }\end{array}$ & & \\
\hline \multirow[t]{3}{*}{ miR-125a } & \multirow[t]{3}{*}{ Downregulation } & Positive regulation of NFKB signaling [19] & TNFAIP3 [19] & \\
\hline & & Inhibits CCL5 production [30] & KLF13 [30] & \\
\hline & & Macrophage polarization $[27,51]$ & & \\
\hline \multirow[t]{6}{*}{ miR-125b } & \multirow[t]{6}{*}{ Downregulation } & Positive regulation of NFKB signaling [19] & TNFAIP3 [19] & \multirow[t]{6}{*}{ CERS** - upregulated [52] } \\
\hline & & Negative regulation of NFKB signaling [18] & MyD88 [18] & \\
\hline & & Activates Macrophages [20] & IRF4 [20] & \\
\hline & & Modulates dendritic cell differentiation [21] & PRDM1 [21] & \\
\hline & & Maintains naïve state in CD4+ T-cells [53] & $\begin{array}{l}\text { IFNy, IL2RB, IL10RA, } \\
\text { PRDM1 [53] }\end{array}$ & \\
\hline & & Negative regulation of inflammation [22] & TNFa [22] & \\
\hline \multirow[t]{2}{*}{ miR-203a } & \multirow[t]{2}{*}{ Upregulation } & Negative regulation of NFKB signaling [25] & Myd88 [25] & \multirow[t]{2}{*}{ Asthma - upregulated [38] } \\
\hline & & Negative regulation of inflammation [54] & TNFa, IL24 [54] & \\
\hline
\end{tabular}

No known immune functions

miR-429 Downregulation

t: The functions described are extracted from a literature search April 2014, excluding studies of cancer. This table is not an exhaustive description of all known functions for each miRNA. All studies were carried out in vitro in specific cell lines, and caution should be taken when extrapolating the data to other cells or biological systems, including clinical disease. Specific miRNA functions and mRNA-target verification have in most cases been determined both by removing the miRNA from the biological system and by stimulating the system with the miRNA. miRNA upregulation after cell stimulation has usually been verified by simple qPCR. miRNA responses to cell stimulation have been included in the table if deemed relevant to virus infection or TLR/NFKB signaling. $\mathrm{t}+\mathrm{X} \rightarrow$ Upregulation ( $\mathrm{Y}$ dep): indicates that in-vitro stimulation of a cell line with molecule or pathogen $\mathrm{X}$ causes upregulation of the miRNA, and that this is dependent upon protein $\mathrm{Y}$.

*DAMPs: Damage-associated molecular pattern molecules.

${ }^{*}$ CERS - Chronic Eosinophilic Rhinosinusitis. 

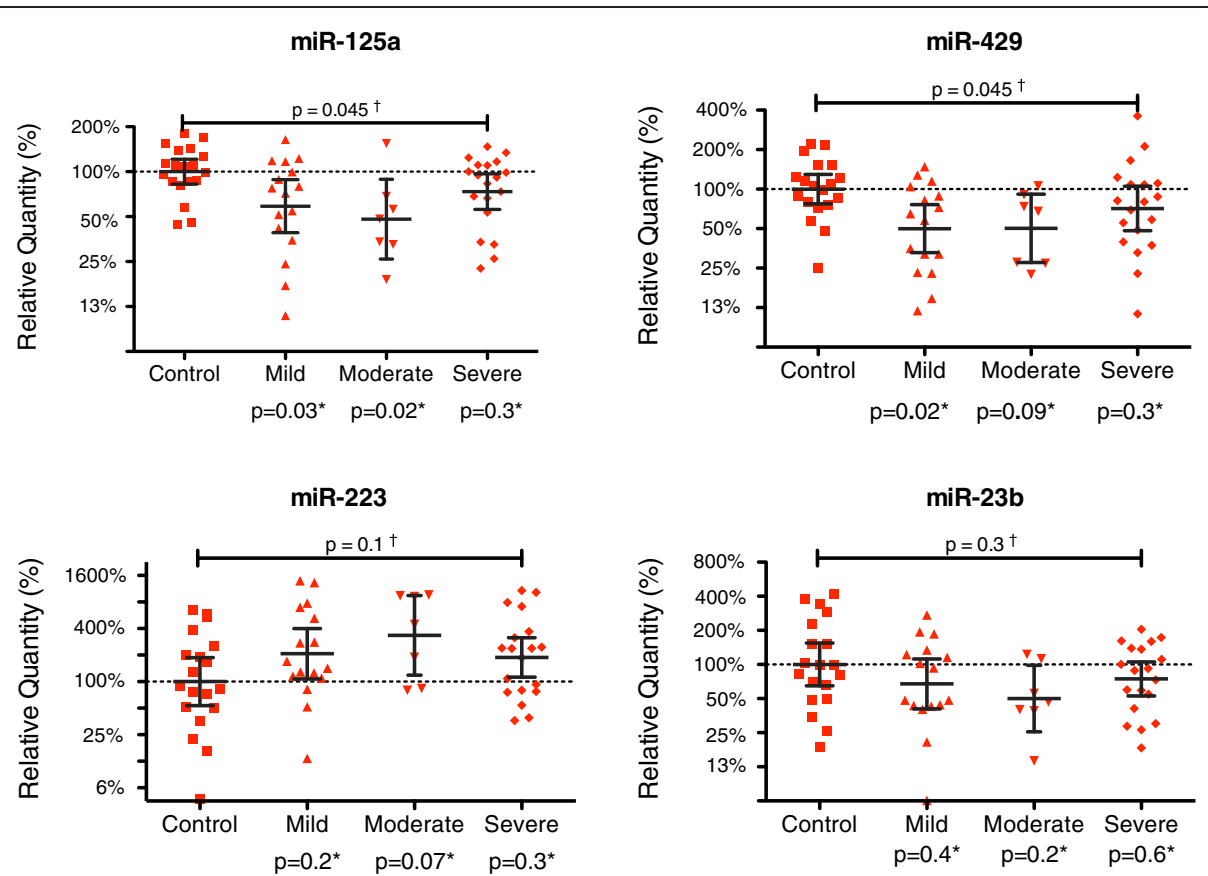

Figure 3 Nasal mucosal miRNA expression according to disease severity in infants infected with Respiratory syncytial virus. Note: Relative quantities of 4 miRNAs assessed for differential expression between disease severity subgroups. Results are calibrated to the mean of the control group, indicated by the dashed line at a relative quantity $100 \%$. Plotted lines indicate the mean with $95 \%$ confidence interval for each group. Numbers in each group: control 19; mild 16; moderate 7; severe 19. For miR-125a there is downregulation in mild and moderate disease groups, but not in the severe group. For miR-429 there is a similar pattern, with downregulation in the mild group but not the severe group. ${ }^{\dagger}$ One-way ANOVA, adjusted for a false discovery rate of $5 \%$. * Dunnett's post-hoc $t$-test after One-way ANOVA, in which mild, moderate and severe disease severity subgroups are compared individually to the control group, with correction for multiple testing. Up- or downregulation is therefore as compared to the control group.

modulation of dendritic cell differentiation [21] and direct targeting of TNF $\alpha$ [22]. miR-34b has been less studied in immunity, but was upregulated in mouse lung tissue after injection of lipopolysaccharide [23].

NF- $\mathrm{KB}$ signaling is modulated by 7 miRNAs regulated in our study: miR-16, miR-29c, miR-34c, miR-125a, miR-125b, miR-155 and miR-203a [16,18,19,24-28]. NF-кB activation following RSV-antigen binding to the pathogen recognition receptors TLR 4 or RIG-1 is a primary stage in the immunological response to RSV [29]. However, excessive NF- $\mathrm{kB}$ activation may also have deleterious effects, and negative regulation is also important. The miRNA regulation pattern in this study implies both positive and negative regulation of NF- $\mathrm{kB}$, consistent with fine-tuning of the immune response to RSV in our samples.

Factors that might cause some infants to have severe disease whilst most infants have mild disease are poorly understood and may aid development of preventative measures and treatments for RSV. We therefore aimed to identify differences in miRNA expression between mild and severe disease. The variation in expression of miR-125a and miR-429 according to disease severity is particularly interesting in the context of innate immunity. miR-125a is a positive regulator of NF-kB via negative regulation of the inhibitory protein TNFAIP3 [27], and a negative regulator of CCL5, an important cytokine in both innate and adaptive immune systems [30]. miR-125a is overexpressed in human macrophages, in an activated phenotype produced by NF-kB activation [27]. Downregulation of miR-125a in children with mild and moderate disease may thus represent reduced macrophage activation and inhibited NF- $\mathrm{kB}$ signaling, which may protect against an excessive innate immune response with a more severe disease phenotype. miR-429 can reactivate dormant Epstein-Barr virus in B-cells [31]. To our knowledge, other functions of miR-429 within the immune system or in RSV disease have not been described.

Upregulation of miR-155 is consistent with an acute inflammatory response. This miRNA is expressed in dendritic cells and in $\mathrm{T}$ and B- lymphocytes and is necessary for their function [32]. miR-155 is produced on TLR4 mediated $N F-\kappa B$ activation and positively regulates myeloid proliferation [33] and dendritic cell maturation [34], which is a necessary step for dendritic cell migration to lymph nodes and antigen presentation.

Several studies have examined in vitro responses to RSV. RSV-stimulation upregulates miR-375 and let-7i in human bronchial epithelial cells $[8,9]$, and let- $7 \mathrm{f}$ in a 
human alveolar cell line [7]. These miRNA were differentially regulated in our microarray, but not in the qPCR (FDR-adjusted $\mathrm{p}=0.054,0.068$ and 0.17 for let-7i, miR375 and let-7f, respectively - see Figure 2). A number of other miRNA identified in these studies were not regulated in our microarray. It is probable that differences in findings between our study and these in vitro studies are due to the cell type analyzed. Our cytology specimens included both nasal respiratory epithelial cells and granulocytes, whilst the in-vitro studies included alveolar or bronchial epithelial cell lines. In addition, the increased biological variation inherent to our clinical samples is likely to reduce the power of our study to observe differences in expression.

To our knowledge, miRNAs have not been studied in clinical disease with respiratory viruses other than in blood samples of patients with influenza A $[35,36]$. This is the first investigation of miRNA expression in clinical samples from RSV-positive infants. Two clinical studies profiled miRNA expression in bronchial epithelial brushings from asthmatic adults $[37,38]$. Findings included upregulation of miR-203a and downregulation of miR-27b, miR-29c, miR-34b and miR-34c - an identical expression pattern to the infants in our study. Early-life RSV infection is associated with later development of asthma [39], making this finding particularly interesting. However, we also found downregulation of let-7d, which targets asthma-associated genes in vitro [40]. Further studies of the role of these miRNA in RSV disease may provide information on mechanisms underlying the association between infantile RSV disease and later development of asthma.

\section{Conclusions}

In summary, we have profiled miRNA expression patterns in the nasal epithelium of infants with acute RSV disease. We find an expression pattern consistent with modulation of both innate and adaptive immune systems, including a number of miRNAs involved in NF-kB regulation or associated with asthma. miR-125a and miR-429 were regulated in mild but not severe disease, warranting further investigation of their role as a regulator of the immune response to RSV.

\section{Competing interests}

The authors declare that they have no financial relationships with any organizations that might have an interest in the submitted work in the previous five years, and no other relationships or activities that could appear to have influenced the submitted work.

\section{Authors' contributions}

$\mathrm{CSI}, \mathrm{TS}, \mathrm{HOF}$ and BN were involved in study design and protocol, interpretation of results and manuscript revision. CSI was responsible for patient inclusion, collection of clinical data, collection of biological samples, statistical analysis and manuscript preparation. TS was responsible for processing biological samples, microarray analysis and $\mathrm{QPCR}$ analysis. All authors read and approved the final manuscript.

\section{Acknowledgements}

We wish to thank the nurses and doctors on the Pediatric Emergency Ward at Akershus University Hospital for much appreciated help in recruiting patients, recording clinical data and collecting nasal specimens. We also stand in gratitude Dr. Katrin Fridrich-Aas, Akershus University Hospital for her assessment of nasal epithelial smears. This study was funded by Akershus University Hospital, 1478 Lørenskog, Norway; by the Institute of Clinical Medicine, University of Oslo, 0316 Oslo, Norway and by Leif Richard Erichsen and Mrs. Maren Hertzberg Erichsen's foundation for the advancement of Norwegian medical research.

\section{Author details}

'Department of Pediatric and Adolescent Medicine, Akershus University Hospital, 1478 Lørenskog, Norway. ${ }^{2}$ Institute of Clinical Medicine, University of Oslo, 0316 Oslo, Norway. ${ }^{3}$ Department of Clinical Molecular Biology and Laboratory Sciences (EpiGen), Akershus University Hospital, 1478 Lørenskog, Norway.

Received: 17 October 2014 Accepted: 10 March 2015

Published online: 25 March 2015

\section{References}

1. Glezen WP, Taber LH, Frank AL, Kasel JA. Risk of primary infection and reinfection with respiratory syncytial virus. Am J Dis Child. 1986;140(6):543-6.

2. Fjaerli HO, Farstad T, Bratlid D. Hospitalisations for respiratory syncytial virus bronchiolitis in Akershus, Norway, 1993-2000: a population-based retrospective study. BMC Pediatr. 2004;4(1):25.

3. Graham BS, Anderson LJ. Challenges and opportunities for respiratory syncytial virus vaccines. Curr Top Microbiol Immunol. 2013;372:391-404.

4. de Fougerolles A, Vornlocher HP, Maraganore J, Lieberman J. Interfering with disease: a progress report on siRNA-based therapeutics. Nat Rev Drug Discov. 2007;6(6):443-53.

5. Montagner S, Orlandi EM, Merante S, Monticelli S. The role of miRNAs in mast cells and other innate immune cells. Immunol Rev. 2013;253(1):12-24.

6. Mi QS, Xu YP, Wang H, Qi RQ, Dong Z, Zhou L. Deletion of microRNA miR-223 increases Langerhans cell cross-presentation. Int J Biochem Cell Biol. 2013:45(2):395-400.

7. Bakre A, Mitchell P, Coleman JK, Jones LP, Saavedra G, Teng M, et al. Respiratory syncytial virus modifies microRNAs regulating host genes that affect virus replication. J Gen Virol. 2012;93(Pt 11):2346-56.

8. Othumpangat S, Walton C, Piedimonte G. MicroRNA-221 modulates RSV replication in human bronchial epithelium by targeting NGF expression. PLoS One. 2012;7(1):e30030

9. Thornburg NJ, Hayward SL, Crowe Jr JE. Respiratory syncytial virus regulates human microRNAs by using mechanisms involving beta interferon and NF-kappaB. mBio. 2012;3(6):e00220-12. doi:10.1128/mBio.00220-12.

10. Inchley CS, Sonerud T, Fjaerli HO, Nakstad B. Reduced Dicer expression in the cord blood of infants admitted with severe respiratory syncytial virus disease. BMC Infect Dis. 2011;11(1):59.

11. Lowell DI, Lister G, Von Koss H, McCarthy P. Wheezing in infants: the response to epinephrine. Pediatrics. 1987;79(6):939-45.

12. Barrett T, Wilhite SE, Ledoux P, Evangelista C, Kim IF, Tomashevsky M, et al. $\mathrm{NCBI}$ GEO: archive for functional genomics data sets-update. Nucleic Acids Res. 2013:41(Database issue):D991-5.

13. Gentleman RC, Carey VJ, Bates DM, Bolstad B, Dettling M, Dudoit S, et al. Bioconductor: open software development for computational biology and bioinformatics. Genome Biol. 2004:5(10):R80.

14. Lopez-Romero P. Pre-processing and differential expression analysis of Agilent microRNA arrays using the AgiMicroRna Bioconductor library. BMC Genomics. 2011;12:64

15. Smyth GK. Linear models and empirical bayes methods for assessing differential expression in microarray experiments. Stat Appl Genet Mol Biol. 2004;3:1-25.

16. Unlu S, Tang S, Wang E, Martinez I, Tang D, Bianchi ME, et al. Damage associated molecular pattern molecule-induced microRNAs (DAMPmiRs) in human peripheral blood mononuclear cells. PLoS One. 2012;7(6):e38899.

17. Takahashi N, Nakaoka T, Yamashita N. Profiling of immune-related microRNA expression in human cord blood and adult peripheral blood cells upon proinflammatory stimulation. Eur J Haematol. 2012;88(1):31-8.

18. Wang Z, Filgueiras LR, Wang $S$, Serezani AP, Peters-Golden $M$, Jancar $S$, et al. Leukotriene B4 enhances the generation of proinflammatory MicroRNAs to 
promote MyD88-dependent macrophage activation. J Immunol. 2014;192(5):2349-56.

19. Kim SW, Ramasamy K, Bouamar H, Lin AP, Jiang D, Aguiar RC. MicroRNAs miR-125a and miR-125b constitutively activate the NF-kappaB pathway by targeting the tumor necrosis factor alpha-induced protein 3 (TNFAIP3, A20). Proc Natl Acad Sci U S A. 2012;109(20):7865-70.

20. Chaudhuri AA, So AY, Sinha N, Gibson WS, Taganov KD, O'Connell RM, et al. MicroRNA-125b potentiates macrophage activation. J Immunol. 2011;187(10):5062-8.

21. Parlato $S$, Bruni R, Fragapane $P$, Salerno D, Marcantonio C, Borghi $P$, et al. IFN-alpha regulates Blimp-1 expression via miR-23a and miR-125b in both monocytes-derived DC and pDC. PLoS One. 2013;8(8):e72833.

22. Huang HC, Yu HR, Huang LT, Huang HC, Chen RF, Lin IC, et al. miRNA-125b regulates TNF-alpha production in CD14+ neonatal monocytes via post-transcriptional regulation. J Leukoc Biol. 2012;92(1):171-82.

23. Hsieh CH, Rau CS, Jeng JC, Chen YC, Lu TH, Wu CJ, et al. Whole blood-derived microRNA signatures in mice exposed to lipopolysaccharides. J Biomed Sci. 2012;19:69.

24. Zhou R, Li X, Hu G, Gong AY, Drescher KM, Chen XM. miR-16 targets transcriptional corepressor SMRT and modulates NF-kappaB-regulated transactivation of interleukin-8 gene. PLoS One. 2012;7(1):e30772.

25. Wei J, Huang $X$, Zhang Z, Jia W, Zhao Z, Zhang Y, et al. MyD88 as a target of microRNA-203 in regulation of lipopolysaccharide or Bacille Calmette-Guerin induced inflammatory response of macrophage RAW264.7 cells. Mol Immunol. 2013:55(3-4):303-9.

26. Wang CM, Wang Y, Fan CG, Xu FF, Sun WS, Liu YG, et al. miR-29c targets TNFAIP3, inhibits cell proliferation and induces apoptosis in hepatitis B virus-related hepatocellular carcinoma. Biochem Biophys Res Commun 2011:411(3):586-92.

27. Graff JW, Dickson AM, Clay G, McCaffrey AP, Wilson ME. Identifying functional microRNAs in macrophages with polarized phenotypes. J Biol Chem. 2012;287(26):21816-25.

28. Li T, Morgan MJ, Choksi S, Zhang Y, Kim YS, Liu ZG. MicroRNAs modulate the noncanonical transcription factor NF-kappaB pathway by regulating expression of the kinase IKKalpha during macrophage differentiation. Nat Immunol. 2010;11(9):799-805.

29. Oshansky CM, Zhang W, Moore E, Tripp RA. The host response and molecular pathogenesis associated with respiratory syncytial virus infection. Future Microbiol. 2009;4(3):279-97.

30. Zhao X, Tang Y, Qu B, Cui H, Wang S, Wang L, et al. MicroRNA-125a contributes to elevated inflammatory chemokine RANTES levels via targeting KLF13 in systemic lupus erythematosus. Arthritis Rheum. 2010;62(11):3425-35.

31. Lin Z, Wang X, Fewell C, Cameron J, Yin Q, Flemington EK. Differential expression of the miR-200 family microRNAs in epithelial and B cells and regulation of Epstein-Barr virus reactivation by the miR-200 family member miR-429. J Virol. 2010;84(15):7892-7

32. Rodriguez A, Vigorito E, Clare S, Warren MV, Couttet $P$, Soond DR, et al Requirement of bic/microRNA-155 for normal immune function. Science. 2007;316(5824):608-11.

33. O'Connell RM, Chaudhuri AA, Rao DS, Baltimore D. Inositol phosphatase SHIP1 is a primary target of miR-155. Proc Natl Acad Sci U S A. 2009;106(17):7113-8.

34. Lu C, Huang X, Zhang X, Roensch K, Cao Q, Nakayama Kl, et al. miR-221 and miR-155 regulate human dendritic cell development, apoptosis, and IL-12 production through targeting of p27kip1, KPC1, and SOCS-1. Blood. 2011;117(16):4293-303

35. Song H, Wang Q, Guo Y, Liu S, Song R, Gao X, et al. Microarray analysis of microRNA expression in peripheral blood mononuclear cells of critically ill patients with influenza A (H1N1). BMC Infect Dis. 2013;13:257.

36. Zhu Z, Qi Y, Ge A, Zhu Y, Xu K, Ji H, et al. Comprehensive characterization of serum MicroRNA profile in response to the emerging avian influenza $A$ (H7N9) virus infection in humans. Virus. 2014;6(4):1525-39.

37. Solberg OD, Ostrin EJ, Love Ml, Peng JC, Bhakta NR, Hou L, et al. Airway epithelial miRNA expression is altered in asthma. Am J Respir Crit Care Med. 2012;186(10):965-74.

38. Jardim MJ, Dailey L, Silbajoris R, Diaz-Sanchez D. Distinct microRNA expression in human airway cells of asthmatic donors identifies a novel asthma-associated gene. Am J Respir Cell Mol Biol. 2012;47(4):536-42.

39. Piedimonte G. Respiratory syncytial virus and asthma: speed-dating or long-term relationship? Curr Opin Pediatr. 2013;25(3):344-9.
40. Kumar M, Ahmad T, Sharma A, Mabalirajan U, Kulshreshtha A, Agrawal A, et al. Let-7 microRNA-mediated regulation of IL-13 and allergic airway inflammation. J Allergy Clin Immunol. 2011;128(5):1077-85. e1071-1010.

41. Griffiths-Jones S, Grocock RJ, van Dongen S, Bateman A, Enright AJ. miRBase: microRNA sequences, targets and gene nomenclature. Nucleic Acids Res. 2006;34(Database issue):D140-4.

42. Zhang X, Guo J, Fan S, Li Y, Wei L, Yang X, et al. Screening and identification of six serum microRNAs as novel potential combination biomarkers for pulmonary tuberculosis diagnosis. PLoS One. 2013;8(12):e81076.

43. Guan Z, Shi N, Song Y, Zhang X, Zhang M, Duan M. Induction of the cellular microRNA-29c by influenza virus contributes to virus-mediated apoptosis through repression of antiapoptotic factors BCL2L2. Biochem Biophys Res Commun. 2012:425(3):662-7.

44. Suarez Y, Wang C, Manes TD, Pober JS. Cutting edge: TNF-induced microRNAs regulate TNF-induced expression of E-selectin and intercellular adhesion molecule-1 on human endothelial cells: feedback control of inflammation. J Immunol. 2010;184(1):21-5.

45. Martinez-Nunez RT, Louafi F, Friedmann PS, Sanchez-Elsner T. MicroRNA-155 modulates the pathogen binding ability of dendritic cells (DCs) by down-regulation of DC-specific intercellular adhesion molecule-3 grabbing non-integrin (DC-SIGN). J Biol Chem. 2009;284(24):16334-42.

46. Panganiban RP, Pinkerton MH, Maru SY, Jefferson SJ, Roff AN, Ishmael FT. Differential microRNA epression in asthma and the role of miR-1248 in regulation of IL-5. Am JClin Exp Immunol. 2012;1(2):154-65.

47. Cai ZG, Zhang SM, Zhang Y, Zhou YY, Wu HB, Xu XP. MicroRNAs are dynamically regulated and play an important role in LPS-induced lung injury. Can J Physiol Pharmacol. 2012;90(1):37-43.

48. Wang $H$, Zhang $P$, Chen $W$, Feng $D$, Jia $Y$, Xie L. Serum microRNA signatures identified by Solexa sequencing predict sepsis patients' mortality: a prospective observational study. PLoS One. 2012;7(6):e38885.

49. Zhou R, Gong AY, Eischeid AN, Chen XM. miR-27b targets KSRP to coordinate TLR4-mediated epithelial defense against Cryptosporidium parvum infection. PLoS Pathog. 2012:8(5):e1002702.

50. Zhou R, Hu G, Gong AY, Chen XM. Binding of NF-kappaB p65 subunit to the promoter elements is involved in LPS-induced transactivation of miRNA genes in human biliary epithelial cells. Nucleic Acids Res. 2010;38(10):3222-32.

51. Banerjee $\mathrm{S}$, Cui H, Xie N, Tan Z, Yang S, Icyuz M, et al. miR-125a-5p regulates differential activation of macrophages and inflammation. J Biol Chem. 2013;288(49):35428-36.

52. Zhang XH, Zhang YN, Li HB, Hu CY, Wang N, Cao PP, et al. Overexpression of miR-125b, a novel regulator of innate immunity, in eosinophilic chronic rhinosinusitis with nasal polyps. Am J Respir Crit Care Med. 2012:185(2):140-51.

53. Rossi RL, Rossetti G, Wenandy L, Curti S, Ripamonti A, Bonnal RJ, et al. Distinct microRNA signatures in human lymphocyte subsets and enforcement of the naive state in CD4+ T cells by the microRNA miR-125b. Nat Immunol. 2011;12(8):796-803.

54. Primo MN, Bak RO, Schibler B, Mikkelsen JG. Regulation of pro-inflammatory cytokines TNFalpha and IL24 by microRNA-203 in primary keratinocytes. Cytokine. 2012;60(3):741-8.

\section{Submit your next manuscript to BioMed Central and take full advantage of:}

- Convenient online submission

- Thorough peer review

- No space constraints or color figure charges

- Immediate publication on acceptance

- Inclusion in PubMed, CAS, Scopus and Google Scholar

- Research which is freely available for redistribution 